http://journal2.um.ac.id/index.php/tekno | ISSN 1693-8739

\title{
Hubungan antara kenyamanan belajar dan ketersediaan sumber belajar dengan kemandirian belajar pada siswa SMK Jurusan Teknik Instalasi Tenaga Listrik di Kabupaten Tulungagung
}

\author{
Setiadi Cahyono Putro ${ }^{1}$, Dyah Lestari ${ }^{2}$, Haya Mei Fatma Bela ${ }^{3}$ \\ 1. Universitas Negeri Malang, Indonesia | setiadicahyono@gmail.com \\ 2. Universitas Negeri Malang, Indonesia | dyah.lestari.ft@um.ac.id \\ 3. Universitas Negeri Malang, Indonesia | hayameibe@gmail.com
}

\begin{abstract}
Abstrak
Tujuan dari penelitian ini yaitu untuk hubungan antara kenyamanan belajar $\left(X_{1}\right)$ dan ketersediaan sumber belajar $\left(\mathrm{X}_{2}\right)$ dengan kemandirian belajar $(\mathrm{Y})$. Penelitian ini menggunakan metode Ex Post Facto dengan rancangan penelitian deskriptif korelasional. Sampel penelitian ini adalah siswa SMK Jurusan Teknik Instalasi Tenaga Listrik di Kabupaten Tulungagung sejumlah 157 responden. Teknik pengumpulan data mengunakan angket. Hasil data angket yang telah memenuhi uji validitas dan reliabilitas yang didapatkan dari skor nilai angket yang diisi oleh responden. Teknik analisis data menggunakan analisis korelasi parsial dan regresi linier. Dari hasil penelitian didapat persamaan regresi $Y=17,764+0.383 X_{1}+0.155 X_{2}$ dengan signifikansi sebesar 0.000 yang artinya ada hubungan positif dan signifikan antara $X_{1}$ dan $X_{2}$ dengan $\mathrm{Y}$ secara simultan.
\end{abstract}

\section{Kata Kunci}

Kenyamanan Belajar, Ketersediaan Sumber Belajar, Dan Kemandirian Belajar 


\section{TEKNO Jurnal Teknologi, Elektro, dan Kejuruan}

http://journal2.um.ac.id/index.php/tekno | ISSN 1693-8739

\section{Pendahuluan}

Pendidikan merupakan hal yang bangsa (Undang-Undang RI No. 20, 2003). Pendidikan akan menjadi maju dalam berkembang ke arah Kemandirian belajar merupakan salah sangat penting bagi kehidupan suatu modal bangsa untuk menjadi lebih yang lebih baik lagi. satu hal penting dalam proses kegiatan pembelajaran (Depdiknas, 2003). Kemandirian belajar merupakan kegiatan belajar aktif yang didorong oleh niat atau motif untuk mengetahui suatu kompetensi guna mengatasi suatu masalah dan dibangun dengan bekal pengetahuan atau kompetensi yang dimiliki (Mudjiman, 2007).

Kemandirian belajar sangat bermanfaat bagi dirinya sendiri. Kurangnya kesadaran siswa terhadap manfaat kemandirian belajar mengakibatkan kemandirian yang ada dalam diri siswa belum berkembang dan suasana proses belajar kurang diminati oleh siswa (Taman, 2012). Untuk menjamin kematangan penerimaan materi yang disampaikan oleh guru, siswa perlu mengimbangi dengan belajar mandiri dan terstruktur (Sutajaya, 2007).

Dalam konteks belajar mandiri, banyak nilai-nilai yang penting untuk dipelihara dan terus ditumbuhkan seperti, keingintahuan, inisiatif, kepercayaan diri, disiplin, dan semangat eksploratif (Sumardiono,2010). Apabila Siswa melakukan belajar mandiri untuk melakukan suatu tindakan-tindakan bebrapa langkah untuk menghasilkan hasil belajar yang tampak maupun hasil yang tidak tampak (Johnson, 2007).

Terdapat enam indikator kemandirian belajar yaitu: (1) ketidaktergantungan pada orang lain; (2) memiliki kepercayaan diri; (3) berperilaku disiplin; (4) memiliki rasa tanggung jawab; (5) berperilaku berdasarkan inisiatif sendiri; dan (6) melakukan kontrol diri (Hidayati dan Listyani ,2010)

Dalam usaha untuk mencapai tujuan belajar perlu diciptakan suasana lingkungan (kondisi) belajar yang lebih kondusif (Sardiman, 2014). Berdasarkan UU RI mengenai Sistem Pendidikan Nasional Nomor 20 Tahun 2003 pasal 1 dijelaskan bahwa pendidikan adalah usaha sadar dan terencana untuk mewujudkan suasana belajar dan proses pembelajaran agar siswa aktif dan dapat mengembangkan potensi dirinya dalam aspek psikologis (UndangUndang RI No. 20,2003)

Sarana dan prasarana yang lengkap dapat mendukung kenyamanan dalam kegiatan pembelajaran. Oleh karena itu setiap sekolah diharapkan untuk memiliki kondisi sarana dan prasarana dengan lengkap dan memadai, agar siswa merasa nyaman dalam mengikuti kegiatan pembelajaran.

Kenyamanan belajar merupakan faktor yang sangat berperan penting dalam kegiatan proses belajar mengajar. Dalam usaha mencapai tujuan belajar diperlukan lingkungan (kondisi) belajar yang lebih kondusif (Sardiman, 2014). Kenyamanan merupakan suatu penilaian yang timbul akibat adanya rangsangan dari lingkungan sekitar yang memberikan keadaan stabil, cukup baik dan memuaskan. 


\section{TEKNO Jurnal Teknologi, Elektro, dan Kejuruan}

http://journal2.um.ac.id/index.php/tekno | ISSN 1693-8739

Tingkat kenyamanan belajar merupakan perasaan nyaman yang dirasakan siswa ketika mengalami proses perubahan tingkah laku individu yang relatif menetap sebagai hasil pengalaman interaksi dengan lingkungan (Saputra, 2015).

Beberapa indikator kenyamanan belajar yaitu: (1) suara; (2) pencahayaan dan sirkulasi udara; (3) kebersihan kelas; (4) keamanan kondisi ruang kelas; (5) kondisi perabot dan pemasangan media; (6) kebisingan; dan (6) lingkungan sekitar (Karwati,2014)

Adapun indikator kondisi lingkungan non fisik yang dikemukanan oleh Sari (2013) yaitu: (1) suasana pembelajaran dikelas; (2) hubungan antar civitas kelas; (3) aktifitas belajar; dan (4) kedisiplinan siswa di dalam kelas (Pujiastuti, 2015). kenyamanan proses belajar mengajar dipengaruhi oleh lingkungan dan suasan dimana proses belajar mengajar berlangsung. Kenyamanan kelas yang baik akan menimbulkan rasa nyaman terhadap siswa ketika memasuki kelas.

Kenyamanan belajar siswa perlu diperhatikan, karena masih kurang dalam penataan ruang kelas, sehingga dalam kegiatan belajar siswa tidak berdesak-desakan ketika duduk. Kebersihan dan ventilasi di kelas perlu diperhatikan, apabila hal tersebut kurang sesuai dengan kondisi yang dapat dirasakan nyaman oleh siswa, maka dapat mengganggu konsentrasi siswa dalm kegiatan belajar.

Belajar merupakan proses yang tidak terlepas dari komponen-komponen yang saling berinteraksi. Salah satu komponen dalam proses tersebut adalah sumber belajar. Sumber belajar merupakan segala daya yang bisa dimanfaatkan untuk kepentinganproses belajar mengajar, baik sebagian maupun keseluruhan, diluar diri siswa yang melengkapi diri mereka pada saat pembelajaran berlangsung (Bustari, 2005).

Sumber belajar merupakan segala sesuatu yang dapat digunakan oleh siswa untuk mendukung terjadinya proses belajar, sehingga memberikan perubahan yang positif. Sumber belajar sangat berperan penting bagi siswa.

Peran penting sumber belajar dapat mempengaruhi dan memungkinkan siswa berubah dari yang semula tidak tahu menjadi tahu, dari yang semula tidak mengerti menjadi mengerti, dari yang tidak terampil menjadi terampil, dan dapat menjadikan bahan untuk membedakan mana yang baik dan mana yang buruk. Sumber belajar dapat mendukung dan menunjang siswa untuk berubah ke arah yang lebih baik dan menuju perkembangan.

Ketersediaan sumber belajar dalam kegiatan pembelajaran sangat berhubungan untuk menciptakan suasana belajar yang nyaman. Kurangnya sumber belajar yang digunakan dalam proses pembelajaran akan berpengaruh terhadap kenyamanan siswa dalam belajar. Kurangnya sumber belajar yang digunakan dalam proses pembelajaran akan menghambat siswa dalam belajar, karena proses pembelajaran menjadi kurang efektif.

Indikator sumber belajar dapat dilihat dari: (1) ketersediaan sumber belajar cetak dan non cetak; (2) pemanfaatan perpustakaan; (3) kondisi lingkungan non fisik; (4) instrumen penunjang pembelajaran; (5) orang sebagai penyampai pesan; dan (6) teknik penyampaian pesan (Mulyasa,2002).

TEKNO Vol. 27 Issue 1, p37-44 | Jurusan Teknik Elektro, Universitas Negeri Malang, Indonesia | Maret 2017

S. C. Putro, D. Lestari, H. M. F. Bela | Hubungan antara kenyamanan belajar dan ketersediaan sumber belajar dengan.. 


\section{TEKNO Jurnal Teknologi, Elektro, dan Kejuruan}

http://journal2.um.ac.id/index.php/tekno | ISSN 1693-8739

Dari paparan indikator sumber belajar buku paket yang digunakan sebagai sumber informasi utama dalam belajar. Biasanya ketersediaan sumber buku paket dipinjamkan oleh pihak sekolah kepada seluruh siswa. Tujuannya untuk menambah motivasi siswa dalam belajar. Kondisi lingkungan non fisik sangtat mendukung proses belajar siswa. Kondisi suasana yang ramai akan mengganggu konsentrasi siswa.

Sumber belajar non cetak berupa PPT, video, alat peraga dan lain-lain dapat melatih serta mengembangkan pemahaman siswa dengan melihat secara langsung. Orang sebagai penyampai pesan yaitu orang yang menyimpan informasi dan menyampaikan pesan secara langsung, seperti guru yang menyampaikan untuk kepentingan belajar. Teknik penyampaian pesan merupakan prosedur yang disiapkan untuk dipergunakan sebagai bahan belajar.

Berdasarkan penjabaran uraian tersebut, maka tujuan dari penelitian ini antara lain untuk: (a) mengetahui tingkat kenyamanan belajar $\left(X_{1}\right)$, tingkat ketersediaan sumber belajar $\left(X_{2}\right)$, dan tingkat kemandirian belajar $(Y)$; (b) mengungkap hubungan antara $X_{1}$ dengan $Y, X_{2}$ dengan $\mathrm{Y}$, serta $\mathrm{X}_{1}$ dan $\mathrm{X}_{2}$ dengan $\mathrm{Y}$.

\section{Metode}

Berdasarkan permasalahan dan tujuan penelitian diatas, maka penelitian ini menggunakan metode penelitian Ex Post Facto dengan rancangan deskriptif korelasional. Penelitian deskriptif korelasional bertujuan untuk mengungkap apakah ada hubungan antara satu variabel dengan variabel lainya baik secara parsial maupun simultan yang hasil penelitiannya dipaparkan dalam bentuk laporan. Variabel penelitian ini yaitu: kenyamanan belajar $\left(\mathrm{X}_{1}\right)$ dan ketersediaan sumber belajar $\left(\mathrm{X}_{2}\right)$ sebagai variabel bebas, serta kemandirian belajar $(\mathrm{Y})$ sebagai variabel terikat.

Populasi penelitian ini adalah siswa kelas X SMK Jurusan Teknik Instalasi Tenaga Listrik sejumlah 197 responden, dengan teknik penentuan sampel yaitu proportional sampling. Sampel penelitian ini sejumlah 157 responden. Teknik pengumpulan data penelitian menggunakan instrumen penelitian berupa kuesioner atau angket. Skala pengukuran instrumen penelitian menggunakan Skala Likert. Dimana angket masing-masing variabel telah memenuhi syarat validitas dan realibilitas. Untuk angket penelitian variabel $\mathrm{X}_{1}$ diperoleh nilai alpha sebesar 0,933 ; angket variabel $X_{2}$ nilai alpha sebesar 0,957 ; dan angket variabel $Y$ nilai alpha sebesar 0,911.

Berdasarkan tujuan penelitian tersebut, maka analisis data yang digunakan yaitu analisis deskriptif dan untuk uji hipotesisnya menggunakan analisa korelasi parsial dan analisis regresi. Sebelum uji hipotesis dilakukan, maka terlebih dahulu diuji prasyarat analisisnya. Apabila semua data penelitian telah memenuhi uji prasyarat analisis. Setelah data dinyatakan memenuhi uji prasyarat analisis, maka dapat dilakukan uji hipotesis dengan bantuan SPSS yang disesuaikan dengan kebutuhan penelitian. Untuk pengambilan keputusannya dengan pada taraf signifikansi 0,05.

TEKNO Vol. 27 Issue 1, p37-44 | Jurusan Teknik Elektro, Universitas Negeri Malang, Indonesia | Maret 2017

S. C. Putro, D. Lestari, H. M. F. Bela | Hubungan antara kenyamanan belajar dan ketersediaan sumber belajar dengan.. 


\section{TEKNO Jumal Teknologi, Eektro, dan Kejuruan}

http://journal2.um.ac.id/index.php/tekno | ISSN 1693-8739

\section{Hasil}

Hasil dari analisis statistik deskriptif untuk data variabel kemandirian belajar dengan berbantuan SPSS 17.0 sebaran datanya ditunjukkan pada Tabel 1.

Tabel 1. Distribusi Variabel Kemandirian Belajar

\begin{tabular}{ccccc}
\hline No & Interval & Klasifikasi & $\mathbf{F}$ & $\%$ \\
\hline 1 & $62,25-84$ & Sangat Baik & 37 & 23,56 \\
2 & $53,5-68,25$ & Baik & 113 & 71,1 \\
3 & $37,75-52,5$ & Kurang Baik & 7 & 4,45 \\
4 & $21-36,75$ & Tidak Baik & 0 & 0 \\
\hline \multicolumn{2}{c}{ Jumlah } & & 157 & $100 \%$ \\
\hline
\end{tabular}

Hasil dari analisis statistik deskriptif untuk data variabel kenyaman belajar dengan berbantuan SPSS 17.0 sebaran datanya ditunjukkan pada Tabel 2.

Tabel 2. Distribusi Variabel Kenyamanan Belajar

\begin{tabular}{ccccc}
\hline No & Interval & Klasifikasi & $\mathbf{F}$ & $\%$ \\
\hline 1 & $94,25-116$ & Sangat Nyaman & 49 & 31,22 \\
2 & $71,5-93,25$ & Nyaman & 107 & 68,15 \\
3 & $48,75-70,5$ & Kurang Nyaman & 1 & 0,63 \\
4 & $26-47,75$ & Tidak Nyaman & 0 & 0 \\
\hline & Jumlah & 157 & $100 \%$ \\
\hline
\end{tabular}

Hasil dari analisis statistik deskriptif untuk data variabel ketersediaan sumber belajar dengan berbantuan SPSS 17.0 sebaran datanya ditunjukkan pada Tabel 3 .

Tabel 3. Distribusi Variabel Ketersediaan Sumber Belajar

\begin{tabular}{ccccc}
\hline No & Interval & Klasifikasi & $\mathbf{F}$ & $\%$ \\
\hline 1 & $82-100$ & Sangat Lengkap & 48 & 30,57 \\
2 & $63-81$ & Lengkap & 106 & 67,52 \\
3 & $44-62$ & Kurang Lengkap & 3 & 1,91 \\
4 & $25-43$ & Tidak Lengkap & 0 & 0 \\
\hline & Jumlah & & 157 & $100 \%$ \\
\hline
\end{tabular}

Hasil uji normalitas dengan Kolmogorov-Smirnov masing-masing variabel $\mathrm{X}_{1}, \mathrm{X}_{2}$, dan $\mathrm{Y}$ berturut-turut diperoleh nilai $(p)$ yaitu 0,$455 ; 0,251 ; 0,4,24$. Dimana setiap variabel memiliki nilai $(p)$ diatas 0,05 yang artinya data terdistribusi normal.

Hasil uji linearitas diperoleh bahwa $X_{1}$ dengan $Y$ terjadi hubungan linear dengan nilai $p$ sebesar 0,000 . Sedangkan untuk $X_{2}$ dengan $Y$ terjadi hubungan yang linear dengan nilai $p$ sebesar 0,000 . 


\section{TEKNO Jurnal Teknologi, Elektro, dan Kejuruan}

http://journal2.um.ac.id/index.php/tekno | ISSN 1693-8739

Hasil uji multikolinearitas diperoleh nilai tolerance $X_{1}$ dan $X_{2}$ yaitu $0,896>0,10$ dan nilai VIF yaitu $1,117<10$. Dari hasil perhitungan tersebut dapat diambil keputusan bahwa hubungan antara $\mathrm{X}_{1}$ dan $\mathrm{X}_{2}$ tidak terjadi multikolinearitas.

Hasil uji autokorelasi diperoleh nilai Durbin-Watson sebesar1,768. Dimana nilai ini diantara $\mathrm{dU} \leq \mathrm{DW} \leq(4-\mathrm{dU})$ yang artinya tidak terjadi autokorelasi.

Sedangkan untuk uji heteroskedastisitas dengan menggunakan kriteria pengambilan keputusan Sig > 0,05. Hasil uji heteroskedastisitas diperoleh bahwa tidak terjadi heteroskedastisitas karena pada diagram Scatterplot titik-titik menyebar dengan pola yang tidak jelas diatas dan dibawah angka nol pada sumbu Y.

Untuk uji hipotesis yang mengungkap hubungan secara parsial antara $X_{1}$ dengan $Y$ adalah positif dan signifikan dengan sig $=0,000<0,05$. Untuk hubungan secara parsial antara $X_{2}$ dengan $Y$ adalah positif dan signifikan dengan sig $=0,022<0,05$. Sedangkan untuk hubungan antara $X_{1}$ dan $X_{2}$ secara simultan dengan $Y$ adalah positif dan signifikan diperoleh nilai $F$ sebesar 46, 234 (sig $=0,000<0,05$ ). Dari hasil penelitian didapat persamaan regresi $Y=$ $17,764+0,383 X_{1}+0,155 X_{2}$

Sumbangan relatif $X_{1}$ dengan $Y$ sebesar $82,30 \%$, sedangkan sumbangan relatif $X_{2}$ dengan $Y$ sebesar $17,70 \%$. Untuk sumbangan efektif $X_{1}$ sebesar $30,85 \%$ dan sumbangan efektif $X_{2}$ sebesar $6,64 \%$. Sedangkan sebesar $62,51 \%$ dipengaruhi oleh variabel dan faktor lain yang tidak diteliti dalam penelitian.

\section{Kesimpulan}

Berdasarkan hasil penelitian yang telah dilakukan dapat diperoleh kesimpulan antara lain:

1. Tingkat kemandirian belajar siswa SMK Jurusan TITL di Kabupaten Tulungagung termasuk dalam kriteria baik. Indikator yang berpengaruh tinggi dalam variabel kemandirian belajar yaitu indikator ketidaktergantungan pada orang lain.

2. Tingkat kenyamanan belajar siswa SMK Jurusan TITL di Kabupaten Tulungagung dalam kriteria nyaman. Indikator yang berpengaruh tinggi dalam variabel kenyamanan belajar yaitu indikator kedisiplinan di dalam kelas.

3. Tingkat ketersediaan sumber belajar siswa SMK Jurusan TITL di Kabupaten Tulungagung dalam kriteria lengkap. Indikator yang berpengaruh tinggi dalam variabel ketersediaan sumber belajar yaitu indikator kondisi lingkungan non fisik.

4. Ada hubungan positif dan signifikan antara kenyamanan belajar dengan kemandirian belajar pada siswa SMK Jurusan TITL di Kabupaten Tulungagung.

5. Ada hubungan positif dan signifikan antara ketersediaan sumber belajar dengan kemandirian belajar pada siswa SMK Jurusan TITL di Kabupaten Tulungagung.

6. Ada hubungan positif dan signifikan antara kenyamanan belajar dan ketersediaan sumber belajar dengan kemandirian belajar pada siswa SMK Jurusan TITL di Kabupaten Tulungagung 


\section{TEKNO Jurnal Teknologi, Elektro, dan Kejuruan}

http://journal2.um.ac.id/index.php/tekno | ISSN 1693-8739

\section{Daftar Rujukan}

Bustari, Meilina. 2005. Pemanfaatan Sumber Belajar dalam Rangka Peningkatan Mutu Sekolah. Jurnal Manajemen Pendidikan, (Online), (http:// library.usu.ac.id/download/fk/06010310.pdf), diakses 26 Januari 2017.

Depdiknas. 2003. Pedoman Analisis Kebutuhan Sarana Pendidikan sekolah Menengah Kejuruan (SMK): Program Keahlian Teknik Elektronika Komunikasi. (Online), (https://www.academia.edu/30471168/KONTRIBUSI_SARANA_PENDIDIKAN_TERHADAP _KUALITAS_PENDIDIKAN_DI_SEKOLAH), diakses 05 Juli 2017.

Hidayati, K \& Listyani. 2010. Pengembangan Instrumen Kemandirian Belajar Siswa. (Online, (http://www.staff.uny.ac.id), diakses 1 Februari 2017.

Johnson, E.B. 2007. Contextual Teaching and Learning: Menjadikan Kegiatan Belajar Mengajar Mengasyikkandan Bermakna. Bandung: MLC.

Karwati, Euis, \& Donni P.J. 2014. Manajemen Kelas. Bandung: Alfabeta.

Mudjiman, Haris,. 2007. Belajar Mandiri (Self-Motivated Learning). Surakarta: UNS Press.

Mulyasa. 2002. Kurikulum Berbasis Kompetensi: Konsep, Karakteristik dan Implementasi. Bandung: Remaja Rosdakarya.

Pujiastuti, Tri. 2015. Pengaruh Kedisiplinan Siswa dan Motivasi Belajar terhadap Prestasi Belajar matematika di MI Kota Salatiga Tahun Ajaran 2014/2015. (Online), (http://perpus.iainsalatiga.ac.id/docfiles/fulltext/2286814586.pdf), diakses 08 Juli 2017.

Saputra, I.N.W. 2015. Hubungan Kondisi Kelas dengan Minat Belajar Siswa Kelas XI Teknik Kendaraan Ringan Di SMK Negeri 6 Malang. Skripsi. Malang: Fakultas Teknik Universitas Negeri Malang.

Sardiman, A.M. 2014. Interaksi dan Motivasi Belajar Mengajar. Jakarta: PT Raja Grafindo Persada.

Sumardiono. 2010. Belajar MandirisMenyiapkan Anak Menghadapi Tantangan Masa Depan. Ebook. (Online), (http://rumahinspirasi.com/materi/eBook Belajar Mandiri RI.pdf), diakses 24 Januari 2017.

Sutajaya, I.M. 2007. Peningkatan Profesionalisme Guru Melalui Pemahaman Terhadap Ergonomi dalam Pembelajaran. Jurnal Pendidikan dan Pengajaran UNDISKHA, Edisi Khusus. (Online), (https://pasca.undiksha.ac.id/images/img_item/934.doc), diakses 23 Juni 2016.

Taman, Abdullah \& Aini.N.P. 2012. Pengaruh Kemandirian Belajar dan Lingkungan Belajar Siswa terhadap Prestasi Belajar Akuntansi Siswa Kelas XI IPS SMA Negeri 1 Sewon Bantul Tahun Ajaran 2010/2011. (Online), (https://www.academia.edu/22201909/jurnal_kemandirian_belajar), diakses 05 Juli 2017.

Undang-Undang RI No. 20 Tahun 2003 tentang Sistem Pendidikan Nasional. Tentang Pendidikan. Tentang Pendidikan. (Online), 


\section{TEKNO Jurnal Teknologi, Elektro, dan Kejuruan}

http://journal2.um.ac.id/index.php/tekno | ISSN 1693-8739

(pendis.kemenag.go.id/file/dokumen/uuno20th2003ttgsisdiknas.pdf), diakses 24 Januari 2017. 